\title{
Correlation between nocturnal oxygen desaturation and glycemic control in diabetic patients with obstructive sleep apnea
}

Amr Mounir Shoukrio

\begin{abstract}
Background: Nocturnal hypoxia occurring in obstructive sleep apnea (OSA) is associated with different metabolic disturbances. The present study aims to correlate between nocturnal oxygen desaturation and levels of glycemic control in patients with type 2 diabetes mellitus (T2DM) and undiagnosed OSA.

Results: The present study included 107 patients with T2DM referred for assessment of sleep-related breathing disorder, there were 62 males (57.94\%) and 45 females (42.05\%), and their age ranged from 42 to 72 years with an average age of $61.29 \pm 6.68$ years. The patients were divided into 2 groups according to the results of overnight pulse oximetry (OPO) and apnea-hypopnea index (AHI) detected by polysomnography. Group 1 included 68 patients, they had moderate to severe OSA and significant nocturnal desaturation, and group 2 included 39 patients with no or mild OSA. The baseline characteristics of the two groups were not significantly different. Group 1 patients showed significantly higher mean Epworth score and more symptoms related to OSA. There was statistically significant difference between the values of ODI (24.88 \pm 9.21 versus $8.94 \pm 2.38)$, AHI $(27.10 \pm 7.68$ versus $9.02 \pm 3.90$ ), and hemoglobin A1c levels ( $8.04 \pm 0.64$ versus $6.79 \pm 0.38$ ) between the two groups. A positive correlation was found between nocturnal oxygen desaturation and levels of HbA1c in group 1 patients reflecting worse glycemic control in patients with moderate to severe OSA.
\end{abstract}

Conclusion: Nocturnal oxygen desaturation occurring in obstructive sleep apnea is associated with poor glycemic control in patients with type 2 diabetes mellitus.

Trial registration: ClinicalTrials.gov, Protocol ID: OPO10-18. Trial registry number: NCT04711083. Date of registration: 14 January 2021, retrospectively registered.

Keywords: Overnight pulse oximetry, Type 2 diabetes mellitus, Polysomnography, Nocturnal desaturation

Correspondence: amr_shoukri@hotmail.com

Department of Chest Diseases, Faculty of Medicine, Ain Shams University, 43 ElMahrouky Street, Heliopolis, Cairo, Egypt

(c) The Author(s). 2021 Open Access This article is licensed under a Creative Commons Attribution 4.0 International License, which permits use, sharing, adaptation, distribution and reproduction in any medium or format, as long as you give appropriate credit to the original author(s) and the source, provide a link to the Creative Commons licence, and indicate if changes were made. The images or other third party material in this article are included in the article's Creative Commons licence, unless indicated otherwise in a credit line to the material. If material is not included in the article's Creative Commons licence and your intended use is not permitted by statutory regulation or exceeds the permitted use, you will need to obtain permission directly from the copyright holder. To view a copy of this licence, visit http://creativecommons.org/licenses/by/4.0/. 


\section{Background}

Obstructive sleep apnea (OSA) is a prevalent illness with a heterogeneous clinical presentation ranging from mild symptoms to severe limitations in the quality of life. This clinical variability may be related to its potential association with major concomitant diseases including diabetes mellitus and a variety of cardiovascular diseases [1].

Obstructive sleep apnea is identified as an important risk factor for many comorbid disorders, leading to resistance to conventional therapies and increase in the risk of mortality [2, 3].

Nocturnal hypoxia has also been suggested to be associated with the development of worsened glycemic control in individuals with T2DM. In support of an association between apnea and glycemic control, a recent pilot study found that the combination of different respiratory events and nocturnal awakenings could predict variability of fasting blood glucose in T2DM patients [4].

Moreover, T2DM individuals with OSA have been shown to exhibit peaks in circulating glucose levels temporarily following oxygen desaturation. Taken together, these studies demonstrate that OSA, and in particular nocturnal hypoxemia, likely leads to elevated glucose levels [4-6].

Polysomnography is the gold standard test for the diagnosis of sleep-related breathing disorders, yet, it is an expensive test with considerable waiting lists and is not available at all care levels. In this respect, overnight pulse oximetry (OPO) was proposed as a simple technique for determining peripheral oxygen saturation (SpO2) during sleep [7].

During a routine OPO, one can get an idea about the mean overnight $\mathrm{SpO} 2$ and lowest $\mathrm{SpO} 2$ during the entire night recording. In general healthy controls, the normal overnight mean oxygen saturation is 96\%. A decreased value points to an underlying cardiopulmonary problem $[8]$.

The use of OPO has emerged substantially as a costeffective tool to screen for OSA [9].

The present study aims to correlate between nocturnal oxygen saturation levels and levels of glycemic control in T2DM patients with undiagnosed obstructive sleep apnea.

\section{Methods}

This study is conducted on patients with T2DM referred to pulmonary clinic for assessment of sleep-related breathing disorders in Mouwasat Hospital in Riyadh, Saudi Arabia, in the period between April 2018 and February 2020.

Written informed consent was collected from all patients. The study was approved by the ethical committee of the hospital and registered in ClinicalTrials.gov (NCT04711083).

\section{Inclusion criteria}

Inclusion criteria include patients $\geq 18$ years diagnosed with T2DM and referred to the respiratory clinic for assessment of sleep-related breathing disorder.

\section{Exclusion criteria}

Exclusion criteria include patients $<18$ years old, those receiving treatment for sleep-disordered breathing (SDB), patients with unstable cardiopulmonary or neurological diseases, and patients who refused to sign the consent.

All patients will be subjected to the following:

- Complete medical history.

- Demographics, measurements of weight, height, body mass index (BMI) in $\mathrm{kg} / \mathrm{m}^{2}$, and neck circumference $(\mathrm{NC})$ in $\mathrm{cm}$.

- Epworth Sleepiness Scale (ESS).

- Measurements of overnight pulse oximetry (OPO).

- Hemoglobin A1c (HbA1c) 1 day before OPO.

- Full night polysomnography study.

\section{Overnight pulse oximetry}

Wrist-worn overnight oximetry was performed using portable Nonin 2500 (Nonin Medical Inc., USA) pulse oximeters with built-in data memory. Overnight recordings were downloaded via cable with $\mathrm{nVision}$ data management software (Nonin Medical Inc.). Graphical and tabulated automated oximetry trend reports were generated for each study [9].

The test was explained to the patients and their caregiver by experienced healthcare staff from the sleep unit. The recording was done at home and started just before going to bed and ended on awakening; the recommended duration was a minimum of $5 \mathrm{~h}$. The following day, the caregiver sent the pulse oximeter to the sleep unit for automatic and manual analysis by the medical staff. The test was valid if at least $4 \mathrm{~h}$ of sleep had been recorded without artifacts in the $\mathrm{SpO} 2$ signal.

Analysis of the recorded data in order to calculate the overnight minimum $\mathrm{SpO} 2$, mean $\mathrm{SpO} 2$, dip frequency (defined as a fall in $\mathrm{SpO} 2$ of $>4 \%$ ), the percentage of oximetry sleep time spent with a $\mathrm{SpO} 2$ of $<90 \%$, and the total oximetry time. Based on the oxygen desaturation index values, recordings were classified as "normal" (< 4.9 desaturation events/hour), "equivocal" (5 to 14.9 desaturation events/hour), or "abnormal" ( $\geq 15$ desaturation events/hour) [10]. 


\section{Polysomnography}

Full night diagnostic polysomnography is done using Alice 6 Diagnostic Sleep system (Philips Respironics Inc., Murrysville, PA, USA). The study was attended by a sleep technician and included electroencephalogram with two frontal derivations, two central derivations and two occipital derivations, right and left eye derivations, nasal pressure, nasal-oral airflow (thermal device), snore sensor, respiratory effort (abdominal and thoracic effort), oxygen saturation with pulse oximetry, submental electromyogram (EMG), and right and left anterior tibialis EMG. Manual interpretation and scoring of the results according to the American Academy of Sleep Medicine Manual for the scoring of sleep events defining apnea events as the cessation of airflow by $\geq 90 \%$ for at least $10 \mathrm{~s}$ and hypopnea events as a reduction in airflow by $\geq$ $30 \%$ for at least $10 \mathrm{~s}$ and oxygen desaturation of $\geq 4 \%$. Apnea-hypopnea index (AHI) was calculated as the total number of apneas (central, mixed, or obstructive) and hypopneas per hour of sleep. Arousal index (AI) was the total number of arousals per hour of sleep [11]. Based on the values of apnea-hypopnea index (AHI), we applied the diagnostic criteria of OSA according to the Third edition of the International Classification of Sleep Disorders and then categorized into normal $(\mathrm{AHI}<5)$, mild (AHI 5-15), moderate (AHI 15-30), and severe $(\mathrm{AHI}>30)[12]$.

\section{Statistical analysis}

Quantitative data were represented as mean $( \pm \mathrm{SD})$, and Qualitative data were represented as number and percentage. Data entry and statistical analysis were
Table 2 Clinical presentation of the study population

\begin{tabular}{|c|c|c|c|}
\hline & Total patients $(n=107)$ & Group1 $(n=68)$ & Group $2(n=39)$ \\
\hline \multicolumn{4}{|c|}{ Snoring, $n(\%)$} \\
\hline Yes & 77 (71.96\%) & $58(85.29 \%)$ & $11(28.20 \%)$ \\
\hline No & $30(28.03 \%)$ & 10 (14.70\%) & 28 (71.79\%) \\
\hline \multicolumn{4}{|c|}{ Daytime sleepiness, n (\%) } \\
\hline Yes & $69(64.48 \%)$ & 61 (89.70\%) & $8(20.51 \%)$ \\
\hline No & $38(35.51 \%)$ & $7(10.29 \%)$ & $31(79.48 \%)$ \\
\hline \multicolumn{4}{|c|}{ Nocturia, $n(\%)$} \\
\hline Yes & $75(70.09 \%)$ & $60(88.23 \%)$ & $15(38.46 \%)$ \\
\hline No & $32(29.90 \%)$ & $8(11.76 \%)$ & $24(61.53 \%)$ \\
\hline \multicolumn{4}{|c|}{ Witnessed apneas, n (\%) } \\
\hline Yes & $52(48.59 \%)$ & 44 (64.70\%) & $8(20.51 \%)$ \\
\hline No & $55(51.40 \%)$ & $24(35.29 \%)$ & $31(79.48 \%)$ \\
\hline \multicolumn{4}{|c|}{ Morning Headache, $n$ (\%) } \\
\hline Yes & $80(74.76 \%)$ & $64(94.11 \%)$ & $16(41.02 \%)$ \\
\hline No & 27 (25.23\%) & 4 (5.88\%) & 23 (58.97\%) \\
\hline
\end{tabular}

performed using (SPSS for Windows, version 20.0; SPSS Inc., Chicago, IL, USA).

\section{Results}

The present study included 107 patients with T2DM, 62 males (57.94\%) and 45 females (42.05\%), and their ages ranged from 42 to 72 years with an average age of 61.29 \pm 6.68 years (Table 1 ). The mean body mass index of the study population was $33.47 \pm 3.15 \mathrm{~kg} / \mathrm{m}^{2}$ (Table 1 ). The mean neck circumference of the patients was $42.14 \pm$

Table 1 Demographic and baseline characteristics of all study population

\begin{tabular}{|c|c|c|c|}
\hline & Total patients $(n=107)$ & Group1 $(n=68)$ & Group $2(n=39)$ \\
\hline \multicolumn{4}{|l|}{ Age (years) } \\
\hline Mean \pm SD & $61.29 \pm 6.68$ & $60.45 \pm 6.84$ & $62.76 \pm 6.13$ \\
\hline Range & $42-72$ & $42-72$ & $48-72$ \\
\hline \multicolumn{4}{|l|}{ Gender } \\
\hline Male, $n(\%)$ & $62(57.94 \%)$ & $41(60.29 \%)$ & $21(53.84 \%)$ \\
\hline Female, $n(\%)$ & $45(42.05 \%)$ & 27 (39.70\%) & $18(46.15 \%)$ \\
\hline \multicolumn{4}{|l|}{ BMI $\left(\mathrm{kg} / \mathrm{m}^{2}\right)$} \\
\hline Mean \pm SD & $33.47 \pm 3.15$ & $33.36 \pm 3.25$ & $33.65 \pm 2.98$ \\
\hline Range & $25.46-43.50$ & $25.46-43.50$ & $27.99-41.52$ \\
\hline \multicolumn{4}{|l|}{$\mathrm{NC}(\mathrm{cm})$} \\
\hline Mean \pm SD & $42.14 \pm 4.75$ & $42.07 \pm 4.82$ & $42.25 \pm 4.62$ \\
\hline Range & $32-50$ & $32-50$ & $33-50$ \\
\hline \multicolumn{4}{|l|}{ ESS* } \\
\hline Mean \pm SD & $14.70 \pm 4.62$ & $17.5 \pm 2.47$ & $9.82 \pm 3.23$ \\
\hline Range & $2-21$ & $13-21$ & $2-14$ \\
\hline
\end{tabular}

$B M I$ body mass index, ESS Epworth Sleeping Scale, NC neck circumference, SD standard deviation ${ }^{*} P<0.00001$ 


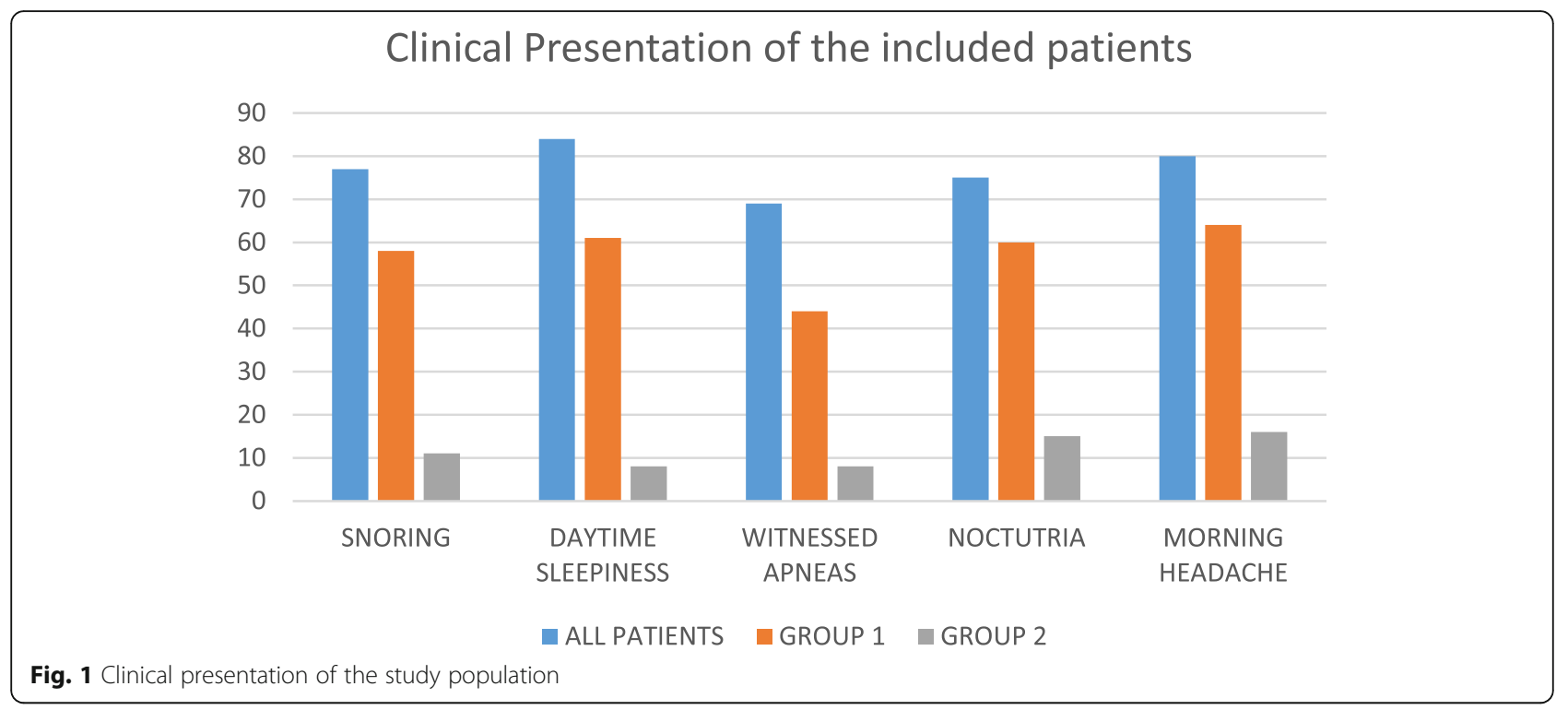

$4.75 \mathrm{~cm}$. Epworth sleeping scale (ESS) showed a mean score of $14.70 \pm 4.62$ (Table 1 ).

Different clinical presentation of the study population related to SDB is shown in Table 2 and Fig. 1.

Overnight pulse oximetry results of the study population showed a mean ODI (desaturation events/hour) of $19.07 \pm 10.71$, polysomnography done for all patients found a mean AHI (events/hour) of $20.51 \pm 10.90$. Mean HbA1c of all patients was $7.57 \pm 0.83$ (Table 3 ).

According to overnight pulse oximetry and polysomnography results, patients were divided into 2 groups, those with confirmed moderate to severe obstructive sleep apnea (AHI $>15$ ) or ODI $\geq 15$ desaturation events/ hour (group 1), and those with no or mild obstructive sleep apnea $(\mathrm{AHI} \leq 15)$, or oxygen desaturation index < 15 desaturation events/hour (group 2).

Group 1 included 68 patients, 41 males (60.29\%) and 27 females (39.70\%), and their age ranged from 42 to 72 years old, with a mean age of $60.45 \pm 6.84$ years (Table 1 ). The mean body mass index of group 1 patients was $33.36 \pm 3.25 \mathrm{~kg} / \mathrm{m}^{2}$, mean neck circumference was 42.07 $\pm 4.82 \mathrm{~cm}$, and mean Epworth score was $17.5 \pm 2.47$ (Table 1). The mean duration of diabetes in group 1 patients was $10.80 \pm 3.35$. The mean $\mathrm{HbA} 1 \mathrm{c}$ was $8.04 \pm$ 0.64 , ODI detected by OPO in group 1 showed a mean of $24.88 \pm 9.21$ (desaturation events/hour), and mean AHI (events/hour) detected by polysomnography was $27.10 \pm 7.68$ (Table 3 ). Positive correlation was found between AHI values and HbA1c values ( $R$ is 0.0282$)$.

Group 2 included 39 patients, 21 males (53.84\%) and 18 females $(46.15 \%)$, and their age ranged from 48 to 72 years old, with a mean age of $62.76 \pm 6.13$ years (Table 1). The mean BMI of group 2 patients was $33.65 \pm 2.98 \mathrm{~kg} / \mathrm{m}^{2}$, mean $\mathrm{NC}$ was $42.25 \pm 4,62$ $\mathrm{cm}$, mean Epworth score was $9.82 \pm 3.23$ (Table 1). The mean duration of diabetes in group 2 patients was $12.89 \pm 3.81$. The mean $\mathrm{HbA} 1 \mathrm{c}$ was $6.79 \pm 0.38$, ODI detected by OPO in group 2 patients showed a mean of $8.94 \pm 2.38$ (desaturation events/hour), and mean AHI (events/hour) detected in polysomnography was $9.02 \pm 3.90$ (Table 3 ).

\section{Discussion}

The present study was performed on T2DM patients who were referred to assess sleep-related breathing disorder, and the results provide evidence that untreated OSA and nocturnal desaturation are associated with impaired glycemic control in type 2 diabetic patients.

Multiple studies have detected a high prevalence of OSA in patients with T2DM [13-15]. The relationship

Table 3 Overnight oximetry, polysomnography, and glycemic control results

\begin{tabular}{lllll}
\hline & Total patients $(\boldsymbol{n}=\mathbf{1 0 7})$ & Group1 $(\boldsymbol{n}=\mathbf{6 8})$ & Group 2 $(\boldsymbol{n}=\mathbf{3 9})$ & $\boldsymbol{P}$ \\
\hline ODI measured by OPO & $19.07 \pm 10.71$ & $24.88 \pm 9.21$ & $8.94 \pm 2.38$ & $<0.00001$ \\
AHI (events/h) & $20.51 \pm 10.90$ & $27.10 \pm 7.68$ & $9.02 \pm 3.90$ & $<0.00001$ \\
HbA1c (\%) & $7.57 \pm 0.83$ & $8.04 \pm 0.64$ & $6.79 \pm 0.38$ & $<0.00001$ \\
\hline
\end{tabular}

AHI apnea-hypopnea index, $\mathrm{HbA1c}$ hemoglobin $\mathrm{A} 1 \mathrm{c}, \mathrm{ODI}$ oxygen desaturation index, OPO overnight pulse oximetry 
between OSA and T2DM may be bidirectional in nature. The occurrence of repeated intermittent hypoxemia and sleep fragmentation are characteristic features of OSA, and these events have been linked to abnormal glucose metabolism in laboratory-based experiments [16].

Our study population was 107 patients with T2DM, 68 (63.55\%) patients (group 1) were found to have moderate to severe OSA associated with significant oxygen desaturation ( $\geq 15$ desaturation events/hour), and 39 (36.44\%) patients (group 2) had less ODI $(<15$ events/hour) and no or mild OSA with AHI ( $<15$ events/hour).

In 2017, the American Diabetes Association recognized OSA as an important comorbidity in T2DM, and the benefits of its management on the quality of life were well reported in those patients [17].

However, the majority of OSA cases in patients with T2DM remain undiagnosed [18].

In the present study, there was no significant difference between the results of the two groups as regards the baseline characteristics. Patients in group 1 were significantly more symptomatic with snoring, morning headache, witnessed apneas, nocturia, and daytime sleepiness. The Epworth score was significantly higher in group 1 patients.

We found a significant difference between the 2 groups as regards HbA1c levels; patients in group 1 with higher ODI and moderate to severe OSA showed significantly higher levels of HbA1c compared to patients in group 2 with no or mild OSA and ODI $<15$ desaturation events/hour.

Multiple studies [13, 19-22] have reported an association between obstructive sleep apnea and HbA1c levels in patients with T2DM. The results of these studies are in accordance with our findings. Polysomnography or respiratory polygraphy have been used in these studies [13, 19-21] to assess the presence and severity of OSA, while in the present study, OPO was used to detect oxygen desaturation index and polysomnography was done to confirm and quantify the severity of OSA.

Overnight pulse oximetry has been proposed as an easy, accessible, cost-effective, and reliable tool for the screening of OSA [1].

Another study done on 162 patients with T2DM and OSA showed results different from our results, there was no independent association between AHI and HbA1c levels. However, in this study, the adjusted HbA1c was not compared among the various OSA severity categories [22].

It is a fact that T2DM is more prevalent among OSA patients compared to those without OSA. A substantial proportion of patients with T2DM suffer from undiagnosed OSA. Thus, the role of OSA in the management of T2DM needs further rigorous assessment [23].

\section{Conclusion}

Nocturnal oxygen desaturation occurring in obstructive sleep apnea is associated with poor glycemic control in patients with type 2 diabetes mellitus.

\section{Abbreviations}

AHI: Apnea-hypopnea index; Al: Arousal index; BMl: Body mass index; EMG: Electromyogram; ESS: Epworth sleeping scale; HbA1c: Hemoglobin A1c; NC: Neck circumference; ODI: Oxyhemoglobin desaturation index; OPO: Overnight pulse oximetry; OSA: Obstructive sleep apnea; SDB: Sleepdisordered breathing; SpO2: Peripheral oxygen saturation; T2DM: Type 2 diabetes mellitus

\section{Acknowledgements}

None

Author's contributions

AS contributed in the concept, design, data collection, data analysis, statistical analysis, manuscript preparation, editing, and review. The author has read and approved the manuscript.

Funding

None

Availability of data and materials

The datasets generated and/or analyzed during the current study are available from the corresponding author on reasonable request.

\section{Declarations}

Ethics approval and consent to participate

Ethics approval from Ethics committee in Mouwasat Hospital in Riyadh, Saudi Arabia, committee reference number is not applicable. Written informed consent is signed by each patient.

\section{Consent for publication}

Written informed consent is signed by each participant accepting to publish the data collected in the study.

\section{Competing interests}

None

Received: 5 February 2021 Accepted: 5 April 2021

Published online: 17 April 2021

\section{References}

1. Del Campo F, Crespo A, Cerezo-Hernández A, Gutiérrez-Tobal GC, Hornero R, Álvarez D (2018) Oximetry use in obstructive sleep apnea. Expert Rev Respir Med 12(8):665-681. https://doi.org/10.1080/17476348.2018.1495563

2. Appleton SL, Gill TK, Lang CJ, Taylor AW, McEvoy RD, Stocks NP et al (2018) Prevalence and comorbidity of sleep conditions in Australian adults: 2016 sleep Health Foundation national survey. Sleep Health 4(1):13-19. https:// doi.org/10.1016/j.sleh.2017.10.006

3. Bonsignore MR, Baiamonte $P$, Mazzuca E, Castrogiovanni A, Marrone O (2019) Obstructive sleep apnea and comorbidities: a dangerous liaison. Multidiscip Respir Med 14(1):8. https://doi.org/10.1186/s40248-019-0172-9

4. Framnes SN, Arble DM (2018) The bidirectional relationship between obstructive sleep apnea and metabolic disease. Front Endocrinol (Lausanne) 9:440

5. Pugliese G, Barrea L, Laudisio D, Salzano C, Aprano S, Colao A, Savastano S, Muscogiuri G (2020) Sleep apnea, obesity, and disturbed glucose homeostasis: epidemiologic evidence, biologic insights, and therapeutic strategies. Curr Obes Rep 9(1):30-38. https://doi.org/10.1007/s13679-020-00369-y

6. Torrella M, Castells I, Gimenez-Perez G, Recasens A, Miquel M, Simó O, Barbeta E, Sampol G (2015) Intermittent hypoxia is an independent marker of poorer glycaemic control in patients with uncontrolled type 2 diabetes. Diabetes Metab 41(4):312-318. https://doi.org/10.1016/j.diabet.2015.01.002

7. Bote SM, Martinez NP, Amarilla CE, Ugalde PF, Gonzalez-Bermejo J, Collado NF, Gamez BJ (2020) Overnight pulse oximetry to determine prognostic factors in subjects with amyotrophic lateral sclerosis. Respir Care 65(8):1128-1134. https://doi.org/10.4187/respcare.07154 
8. Singh S, Khan SZ, Singh D, Verma S, Talwar A (2020) The uses of overnight pulse oximetry. Lung India 37(2):151-157. https://doi.org/10.4103/lungindia. lungindia_302_19

9. Zampoli M, Abousetta N, Vanker A (2018) Overnight oximetry as a screening tool for moderate to severe obstructive sleep apnoea in south African children. S Afr Med J 109(1):23-26. https://doi.org/10.7196/SAMJ.2018.v1 0911.13033

10. Staniforth AD, Kinnear WJ, Starling R, Cowley AJ (1998) Nocturnal desaturation in patients with stable heart failure. Heart. 79(4):394-399. https://doi.org/10.1136/hrt.79.4.394

11. Berry RB, Brooks R, Gamaldo C, Harding SM, Lloyd RM, Quan SF et al (2017) AASM scoring manual updates for 2017 (version 2.4). J Clin Sleep Med 13(5): 665-666

12. Sateia MJ (2014) International classification of sleep disorders-third edition: highlights and modifications. Chest. 146(5):1387-1394. https://doi.org/10.13 78/chest.14-0970

13. Grimaldi D, Beccuti G, Touma C, Van Cauter E, Mokhlesi B (2014) Association of obstructive sleep apnea in REM sleep with reduced glycemic control in type 2 diabetes: therapeutic implications. Diabetes Care 37(2):355-363. https://doi.org/10.2337/dc13-0933

14. Resnick HE, Redline S, Shahar E, Gilpin A, Newman A, Walter R et al (2003) Diabetes and sleep disturbances: findings from the sleep heart health study. Diabetes Care 26(3):702-709. https://doi.org/10.2337/diacare.26.3.702

15. Einhorn D, Stewart DA, Erman MK, Gordon N, Philis-Tsimikas A, Casal E (2007) Prevalence of sleep apnea in a population of adults with type 2 diabetes mellitus. Endocr Pract 13(4):355-362. https://doi.org/10.4158/ EP.13.4.355

16. Reutrakul S, Mokhlesi B (2017) Obstructive sleep apnea and diabetes a state of the art review. CHEST 152(5):1070-1086. https://doi.org/10.1016/j.chest.2 017.05.009

17. American Diabetes Association (2017) Standards of medical Care in Diabetes-2017. Diabetes Care 40(Suppl 1):S1-S142

18. Heffner JE, Rozenfeld Y, Kai M, Stephens EA, Brown LK (2012) Prevalence of diagnosed sleep apnea among patients with type 2 diabetes in primary care. Chest. 141(6):1414-1421. https://doi.org/10.1378/chest.11-1945

19. Aronsohn RS, Whitmore H, Van Cauter E, Tasali E (2010) Impact of untreated obstructive sleep apnea on glucose control in type 2 diabetes. Am J Respir Crit Care Med 181(5):507-513. https://doi.org/10.1164/rccm.200909-1423OC

20. Kent BD, Grote L, Ryan S, Pépin J-L, Bonsignore MR, Tkacova R et al (2014) Diabetes mellitus prevalence and control in sleep-disordered breathing: the European sleep apnea cohort (ESADA) study. Chest. 146(4):982-990. https:// doi.org/10.1378/chest.13-2403

21. Priou P, Le VM, Meslier N, Chollet S, Pigeanne T, Masson P et al (2015) Association between obstructive sleep apnea severity and glucose control in patients with untreated versus treated diabetes. J Sleep Res 24(4):425431. https://doi.org/10.1111/jsr.12278

22. Lam DC, Lui MM, Lam JC, Ong LHY, Lam KSL, Ip MSM (2010) Prevalence and recognition of obstructive sleep apnea in Chinese patients with type 2 diabetes mellitus. Chest. 138(5):1101-1107. https://doi.org/10.1378/chest.100596

23. Malik JA, Masoodi SR, Shoib S (2017) Obstructive sleep apnea in type 2 diabetes and impact of continuous positive airway pressure therapy on glycemic control. Indian J Endocrinol Metab 21(1):106-112

\section{Publisher's Note}

Springer Nature remains neutral with regard to jurisdictional claims in published maps and institutional affiliations.

\section{Submit your manuscript to a SpringerOpen ${ }^{\circ}$ journal and benefit from:}

- Convenient online submission

- Rigorous peer review

- Open access: articles freely available online

- High visibility within the field

- Retaining the copyright to your article

Submit your next manuscript at $\boldsymbol{\nabla}$ springeropen.com 